\title{
Loss of endothelial $\mathrm{K}_{\mathrm{ATP}}$ channel-dependent, NO-mediated dilation of endocardial resistance coronary arteries in pigs with left ventricular hypertrophy
}

\author{
${ }^{1,2}$ Marie-Eve Gendron, ${ }^{*, 1}$ Eric Thorin \& ${ }^{1}$ Louis P. Perrault
}

${ }^{1}$ Department of Surgery and Research Center, Institut de Cardiologie de Montréal, 5000, rue Bélanger, Montréal, Québec, Canada H1T 1 C8 and ${ }^{2}$ Department of Pharmacology, Université de Montréal, Canada

\begin{abstract}
1 The influence of left ventricular hypertrophy ( $\mathrm{LVH})$ on the endothelial function of resistance endocardial arteries is not well established. The aim of this study was to characterise the mechanisms responsible for UK-14,304 ( $\alpha_{2}$-adrenoreceptor agonist)-induced endothelium-dependent dilation in pig endocardial arteries isolated from hearts with or without $\mathrm{LVH}$.

2 LVH was induced by aortic banding 2 months before determining endothelial function. Following euthanasia, hearts were harvested and endocardial resistance arteries were isolated and pressurised to $100 \mathrm{mmHg}$ in no-flow conditions. Vessels were preconstricted with acetylcholine (ACh) or high external $\mathrm{K}^{+}\left(40 \mathrm{mmoll}^{-1} \mathrm{KCl}\right)$. Results are expressed as mean \pm s.e.m.

3 UK-14,304 induced a maximal dilation representing $79 \pm 6 \%(n=8)$ of the maximal diameter. NO synthase (L-NNA, $10 \mu \mathrm{moll}^{-1}, n=7$ ) or guanylate cyclase (ODQ, $\left.10 \mu \mathrm{moll}^{-1}, n=4\right)$ inhibition reduced $(P<0.05)$ UK-14,304-dependent dilation to $35 \pm 6$ and $18 \pm 7 \%$, respectively. Apamin and charybdotoxin reduced $(P<0.05)$ to $39 \pm 8 \% \quad(n=4)$ the dilation induced by UK-14,304. In depolarised conditions, however, this dilation was prevented $(P<0.05)$.

4 UK-14,304-induced dilation was reduced $(P<0.05)$ by glibenclamide $\left(\mathrm{Glib}, 1 \mu \mathrm{moll}^{-1}\right)$, a $\mathrm{K}_{\text {ATP }}$ channel blocker, either alone $(35 \pm 10 \%, n=5)$ or in combination with L-NNA $(34 \pm 9 \%, n=4)$.

5 In LVH, UK-14,304-induced maximal dilation was markedly reduced $(25 \pm 4 \%, P<0.05)$ compared to control; it was insensitive to L-NNA $(21 \pm 5 \%)$ but prevented either by the combination of L-NNA, apamin and charybdotoxin, or by $40 \mathrm{mmol}^{-1} \mathrm{KCl}$.

6 Activation of endothelial $\alpha_{2}$-adrenoreceptor induces an endothelium-dependent dilation of pig endocardial resistance arteries. This dilation is in part dependent on NO, the release of which appears to be dependent on the activation of endothelial $\mathrm{K}_{\mathrm{ATP}}$ channels. This mechanism is blunted in $\mathrm{LVH}$, leading to a profound reduction in UK-14,304-dependent dilation.

British Journal of Pharmacology (2004) 143, 285-291. doi:10.1038/sj.bjp.0705937
\end{abstract}

Keywords: Endothelium; coronary arterioles; LVH; NO; hyperpolarisation; $\mathrm{K}_{\mathrm{ATP}}$ channels; $\alpha_{2}$-adrenergic receptor agonist

Abbreviations: ACh, acetylcholine; Apa, apamin; BK, bradykinin; Chtx, charybdotoxin; $E_{\max }$, maximal dilation; EDHF, endothelium-derived hyperpolarizing factor; Glib, glibenclamide; indo, indomethacin; $\mathrm{K}_{\mathrm{ATP}}$, ATP-sensitive $\mathrm{K}^{+}$ channels; $\mathrm{K}_{\mathrm{Ca}}, \mathrm{Ca}^{2+}$-sensitive $\mathrm{K}^{+}$channel; L-NNA, $N \omega$-nitro-L-arginine; LVH, left ventricular hypertrophy; MT, myogenic tone; NO, nitric oxide; ODQ, $1 \mathrm{H}-[1,2,4]$ Oxadiazolo[4,3a]quinoxaline-1-one; $\mathrm{PGI}_{2}$, prostacyclin; PSS, physiological salt solution; SNP, sodium nitroprusside

\section{Introduction}

Left ventricular hypertrophy $(\mathrm{LVH})$ is the main morphological adaptive change of the heart in response to a chronic increase in pressure. $\mathrm{LVH}$ is a common clinical finding affecting $23 \%$ of men and $33 \%$ of women over the age of 59 (Savage et al., 1987). LVH is characterised by an increased myocardial mass, which requires an increase in coronary blood flow to maintain function. Compression of the microvasculature and lack of blood supply, however, may be associated with myocardial ischemia (Pichard et al., 1981; Marcus et al., 1982; Opherk et al., 1984). In patients with LVH, arteriolar density was found to be identical to that of healthy controls, whereas arteriolar medial area and peri-arteriolar collagen area were

*Author for correspondence; E-mail: Eric.Thorin@ICM-MHI.org Advance online publication: 23 August 2004 increased (Mundhenke et al., 1997). Although such structural changes may partly account for the impaired coronary reserve in LVH (Kozakova et al., 2000; Rajappan et al., 2002; 2003), additional vascular changes must be involved.

Endothelial dysfunction, a common feature of vascular diseases, is characterised by a reduced dilatory capacity (Taniyama \& Griendling, 2003). Endothelium-dependent dilation is reduced in patients with $\mathrm{LVH}$, in addition to coronary flow reserve, whereas the minimum coronary resistance is increased (Treasure et al., 1992; 1993; Egashira et al., 1995; Houghton et al., 1998; 2003; Kozakova et al., 2000; Di Bello et al., 2002; Rajappan et al., 2002; 2003). As previously shown in human (Houghton et al., 1998), we reported in pigs that the endothelium-dependent relaxation of large epicardial coronary arteries was impaired in $\mathrm{LVH}$ 
following 2 months of aortic banding (Malo et al., 2003). Although free radicals are implicated in all cardiovascular diseases (for review, Taniyama \& Griendling, 2003), the cellular mechanisms leading to this dysfunction are unclear. In addition, it is unclear whether endothelial microvascular function is similarly altered. Our previous data (Thorin, 2001) and those of others (Thollon et al., 1999) demonstrate that cardiovascular diseases do not alter endothelial function in general, but affect particular receptor systems. To address this issue, we have investigated the mechanisms of action of $\alpha_{2}$ adrenergic receptor $\left(\alpha_{2}-\mathrm{AR}\right)$-mediated NO-dependent dilation of pressurised endocardial resistance arteries isolated from healthy pigs and pigs with LVH. The results demonstrate that $\mathrm{NO}$ production is not impaired in $\mathrm{LVH}$; however, $\alpha_{2}$ - $\mathrm{AR}$ coupling leading to NO release is blunted.

\section{Methods}

\section{Animals}

In total, 70 2-month-old male Landrace swine $(25 \pm 3 \mathrm{~kg})$ were maintained and tested in accordance with the recommendations of the guidelines on the care and use of laboratory animals issued by the Canadian Council on Animal Research and the guidelines of the Animal Care, and were approved by the local committee. Two experimental groups were studied: a control group, which consisted of swine killed by exsanguination without aortic banding and a LVH group, with aortic banding for a period of 60 days before killing.

\section{Surgical procedure}

Induction of LVH was performed by aortic banding as previously described (Malo et al., 2003). Briefly, anaesthesia was induced by intramuscular injection of ketamine $\left(20 \mathrm{mg} \mathrm{kg}^{-1}\right)$ and xylazine $\left(2 \mathrm{mg} \mathrm{kg}^{-1}\right)$. It was supported by halothane $1 \% \mathrm{vv}^{-1}$ during artificial ventilation with an $\mathrm{O}_{2} /$ air mixture. Arterial blood gases were monitored. Acidosis was balanced with $8.4 \%$ sodium. A catheter was placed in an auricular vein for intravenous infusion during operation. A femoral catheter was placed to monitor arterial pressure and for arterial blood sampling. A left thoracotomy was performed in the third intercostal space. The ascending aorta and the pulmonary vein were carefully separated. An umbilical tape was placed $3 \mathrm{~cm}$ above the coronary ostia of the aorta, gently constricted to obtain a negative systolic gradient of $15 \mathrm{mmHg}$ (measured by monitoring the systemic arterial pressure distally to the banding site) and then tied. The pericardium was loosely closed and the chest was closed in multiple layers.

\section{Sacrifice and coronary microvessels harvesting}

In total, 4-month-old sham swine (Control, $40 \pm 2 \mathrm{~kg}$ ) and LVH $(42 \pm 2 \mathrm{~kg})$ swine with 60 days of aortic banding were anesthetised using the same approach as for the surgical procedure. After exsanguination, the thorax was reopened through a median sternotomy to excise the heart, which was immediately placed in cold $\left(4^{\circ} \mathrm{C}\right)$ physiological salt solution (PSS) of the following composition $\left(\mathrm{mmoll}^{-1}\right)$ : $\mathrm{NaCl} 130 ; \mathrm{KCl}$ 4.7; $\mathrm{CaCl}_{2}$ 1.6; $\mathrm{MgSO}_{4}$ 1.17; $\mathrm{NaHCO}_{3} 14.9 ; \mathrm{KH}_{2} \mathrm{PO}_{4} 1.18$; EDTA 0.026; glucose 10; and oxygenated with $12 \% \quad \mathrm{O}_{2} / 5 \%$
$\mathrm{CO}_{2} / 83 \% \mathrm{~N}_{2}$ (pH 7.4). Hearts were weighed and a section of the left ventricle was isolated and placed in a Petri dish containing cold PSS supplemented with indomethacin (10 $\mu \mathrm{moll}^{-1}$, cyclooxygenase inhibitor). Subendocardial coronary microvessels $(100-250 \mu \mathrm{m}$ in external diameter) were dissected out from the anterior-free wall of the left ventricle.

\section{Morphometric analysis}

Subendocardial arterioles (100-250 $\mu$ m external diameter) were dissected with a myocardial block, fixed in formalin $10 \%$ and cut transversely. Slices were stained with Verhoeff. Total vessel area and lumen area were determined by digital planimetry using a video microscope linked to a computer and a customised software (Scion image 1.6, Frederick, MD, U.S.A.). Wall area was determined by subtraction of the lumen area from the total area. In order to obtain comparable data at variable diameters, the wall to lumen ratio was calculated.

\section{Coronary microvessel studies}

Vessels were placed in a $2 \mathrm{ml}$ plexiglass organ chamber containing oxygenated PSS warmed at $37^{\circ} \mathrm{C}$, cannulated with dual glass micropipettes, and secured with $10-0$ nylon monofilaments sutures as previously described (Véquaud \& Thorin, 2001). Vessels were pressurised to $100 \mathrm{mmHg}$ in a no-flow state. This internal pressure was selected based on preliminary experiments demonstrating that within a range of 80 $120 \mathrm{mmHg}$, myogenic responses were optimal in the two groups of vessels. Myogenic tone $(n=7)$ represented $18 \pm 3$, $20 \pm 4$ and $19 \pm 4 \%$ at 80,100 and $120 \mathrm{mmHg}$ in the control group, and $11 \pm 4,14 \pm 4$ and $17 \pm 4 \%$ at 80,100 and $120 \mathrm{mmHg}$ in the LVH group. With an inverted microscope connected to a video camera, the vessel image was projected onto a black and white monitor. A video dimension analyzer (Living Systems Intrumentation, Burlington, VT, U.S.A.) was used to acquire online internal lumen diameter. Vessels were allowed to equilibrate in the organ chamber for $50-60 \mathrm{~min}$ before initiation of the experimental protocols.

\section{Study protocols}

After equilibration, the arterial segments were constricted by extraluminal addition of acetylcholine (ACh; $10 \mu \mathrm{moll}^{-1}$ ), which induced a reduction in diameter representing $75 \%$ of the maximal diameter, that is, $44 \pm 5 \mu \mathrm{m}$ from $188 \pm 10 \mu \mathrm{m}$ in control and $50 \pm 5 \mu \mathrm{m}$ from $205 \pm 5 \mu \mathrm{m}$ in LVH vessels. Single cumulative concentration-response curve was obtained, either to $\mathrm{UK}-14,304\left(1 \mathrm{pmol}^{-1}\right.$ to $\left.0.3 \mu \mathrm{moll}^{-1}\right)$, to bradykinin (BK; $1 \mathrm{fmoll}^{-1}$ to $0.3 \mu \mathrm{moll}^{-1}$ ), or to sodium nitroprusside (SNP; $1 \mathrm{nmol}^{-1}$ to $\left.0.3 \mathrm{mmoll}^{-1}\right)$. All drugs were applied extraluminally. At the end of the protocol, the maximal diameter $\left(D_{\max }\right)$ was determined by changing the PSS to a $\mathrm{Ca}^{2+}$-free PSS containing SNP $\left(10 \mu \mathrm{moll}^{-1}\right)$ and EGTA (ethylene glycol$\operatorname{bis}\left(\beta\right.$-aminoethylether)- $N, N, N^{\prime}, N^{\prime}$-tetraacetic acid, $1 \mathrm{mmoll}^{-1}$ ).

In another series of experiments, vessels were constricted by a $40 \mathrm{mmoll}^{-1} \mathrm{KCl}$-PSS depolarising solution added to the organ chamber. Depolarisation induced a reduction in diameter representing $75 \%$ of the maximal diameter, that is, $49 \pm 7 \mu \mathrm{m}$ from $199 \pm 14 \mu \mathrm{m}$ in control and $60 \pm 10 \mu \mathrm{m}$ from $222 \pm 8 \mu \mathrm{m}$ in LVH vessels. Single cumulative concentration- 
response curve to the agonist was obtained, followed by the determination of the $D_{\max }$, as described above.

All experiments were performed in the presence of indomethacin $\left(10 \mu \mathrm{moll}^{-1}\right)$. Inhibitors were added in the bath (extraluminally) after the equilibration period and $20 \mathrm{~min}$ before initiation of the experiment (dilation to one agonist on AChinduced constriction). NO formation was inhibited by $N \omega$-nitroL-arginine (L-NNA; $10 \mu \mathrm{moll}^{-1}$ ), an inhibitor of NO synthase. Cyclic GMP formation was inhibited by $1 \mathrm{H}-[1,2,4]$ Oxadiazolo[4,3-a]quinoxaline-1-one (ODQ, $10 \mu \mathrm{moll}^{-1}$ ), an inhibitor of the soluble guanylate cyclase. Glibenclamide $\left(1 \mu \mathrm{moll}^{-1}\right)$ was used to block ATP-dependent potassium channels $\left(\mathrm{K}_{\text {ATP }}\right)$. Finally, to further confirm the involvement of a putative endothelium-derived hyperpolarizing factor (EDHF), apamin $\left(1 \mu \mathrm{mol}^{-1}\right)$ and charybdotoxin $\left(0.1 \mu \mathrm{moll}^{-1}\right)$ were used to block calcium-activated potassium channels $\left(\mathrm{K}_{\mathrm{Ca}}\right)$, the small conductance $\mathrm{K}_{\mathrm{Ca}}\left(\mathrm{SK}_{\mathrm{Ca}}\right)$ and the intermediate conductance $\mathrm{K}_{\mathrm{Ca}}\left(\mathrm{IK}_{\mathrm{Ca}}\right) /$ big conductance $\mathrm{K}_{\mathrm{Ca}}\left(\mathrm{BK}_{\mathrm{Ca}}\right)$, respectively.

\section{Drugs}

Acetylcholine, bradykinin, UK-14,304, sodium nitroprusside, indomethacin, $\quad N \omega$-nitro-L-arginine, $\quad 1 \mathrm{H}-[1,2,4]$ Oxadiazolo[4,3a]quinoxaline-1-one (ODQ), glibenclamide, apamin and charybdotoxin were obtained from Sigma Chemical Co., St Louis, MO, U.S.A. All drugs were dissolved in ultrapure distilled water except for glibenclamide, which was dissolved in DMSO as a stock solution $\left(10 \mathrm{mmol}^{-1}\right)$ and dissolved in PSS to obtain the final dilution $\left(1 \mu \mathrm{moll}^{-1}\right)$, and indomethacin, which was dissolved in ethanol as a stock solution $\left(10 \mathrm{mmoll}^{-1}\right)$. Stock solutions were stored at $-20^{\circ} \mathrm{C}$. Dilutions were prepared daily.

\section{Data analysis}

In every case, $n$ refers to the number of animals used in each protocol. Half-maximum effective concentration $\left(\mathrm{EC}_{50}\right)$ of each drug was measured from each individual concentrationresponse curve using a logistic curve-fitting program (Allfit, Dr DeLéan, Université de Montréal, Montréal, QC, Canada). The $p \mathrm{D}_{2}$ value, the negative $\log$ of the $\mathrm{EC}_{50}$, was obtained. Continuous variables are expressed as mean \pm standard error of the mean (s.e.m.). For each protocol, basal diameter in no-flow condition was determined at the end of the 50-min equilibration period. Myogenic tone, which is a reduction in diameter induced by an increase in luminal pressure, was measured and expressed as percentage of the $D_{\max }$. Agonistinduced dilation is expressed as a percentage of the $D_{\max }$. ANOVA were performed to compare concentration-response curves. Differences were considered to be statistically significant when the $P$-value was $<0.05$ (Scheffe's F-test).

\section{Results}

\section{Baseline parameters}

In total, 60 days of aortic banding led to an increase $(P<0.05)$ in heart to body weight ratio $\left(6.8 \pm 0.9 \mathrm{~g} \mathrm{~kg}^{-1}\right)$ compared to the control group $\left(5.7 \pm 1.3 \mathrm{~g} \mathrm{~kg}^{-1}\right)$. The haemodynamic characteristics of LVH in this model have been published (Malo et al., 2003). Briefly, left diastolic and end-diastolic intraventricular pressures were increased and relaxation of the left ventricle was impaired. In addition, morphometric and haemodynamic parameters did not differ between control and sham-operated animals (Malo et al., 2003).

The wall to lumen ratio of resistance arteries (100-250 $\mu \mathrm{m}$ external diameter) increased from $1.5 \pm 0.1(n=6)$ in control vessels to $2.3 \pm 0.3(n=8)$ in $\mathrm{LVH}$.

Isolated and pressurised endocardial arteries developed myogenic tone (Table 1). This reduction in diameter induced by the intraluminal pressure was not different between the two groups. Whereas pharmacological inhibition of the NO synthase had no influence on the myogenic tone of arteries isolated from control hearts, it increased myogenic tone $(P<0.05)$ in vessels isolated from $\mathrm{LVH}$ hearts. In contrast, blockade of $\mathrm{K}_{\text {ATP }}$ channel with glibenclamide increased $(P<0.05)$ myogenic tone in control but not $\mathrm{LVH}$ vessels. Guanylate cyclase inhibition with ODQ augmented myogenic tone more $(P<0.05)$ in arteries from control than $\mathrm{LVH}$ hearts, whereas dual inhibition of the $\mathrm{NO}$ pathway and the $\mathrm{K}_{\mathrm{Ca}}$ channels increased myogenic tone similarly in both groups (Table 1). In vessels isolated from control pigs, apamin and charybdotoxin alone increased myogenic tone to $57 \pm 8 \%$ of $D_{\max }(n=4)$.

\section{UK-14,304 induced dilation}

The $\alpha_{2}$-AR agonist UK-14,304 induced an endotheliumdependent dilation of pressurised coronary microvessels. This dilation (Table 2$)$ was reduced $(P<0.001)$ in the LVH group when compared to controls (Figure 1). The dilatation was insensitive to L-NNA in the LVH group, whereas addition of L-NNA impaired $(P<0.001)$ the maximal dilation of control arteries. The guanylate cyclase inhibitor ODQ reduced $(P<0.05)$ the dilation of control vessels to a level comparable to that induced by L-NNA (Table 2).

UK-14,304-induced dilation was abolished in both controls and LVH groups under depolarised conditions (high external $\mathrm{K}^{+}$). When present, L-NNA only partially prevented UK14,304-induced responses (Figure 1), suggesting an additional mechanism of action by the latter that may be independent of NO synthesis. To test whether the actions of UK-14,304 may be due to depolarisation, dilations induced by this compound were examined in the presence of glibenclamide $\left(1 \mu \mathrm{moll}^{-1}\right)$.

Table 1 Myogenic tone of pressurised coronary endocardial arteries

$\begin{array}{llrcr}\text { Experimental conditions } & \text { Control } & \mathrm{n} & \text { LVH } & \mathrm{n} \\ & & & & \\ \text { PSS } & 13 \pm 3 & 23 & 8 \pm 2 & 17 \\ \text { + L-NNA } & 14 \pm 6 & 7 & 33 \pm 11^{*} & 5 \\ \text { + Glib } & 36 \pm 7^{*} & 9 & 9 \pm 5^{\dagger} & 5 \\ \text { + ODQ } & 75 \pm 5^{*} & 10 & 46 \pm 13^{*} \dagger & 6 \\ \text { + L-NNA + Apa + Chtx } & 63 \pm 25^{*} & 3 & 51 \pm 14^{*} & 3\end{array}$

Myogenic tone ( $\left.\% D_{\max }\right)$ was measured in the absence (PSS) or $20 \mathrm{~min}$ after preincubation of the tissues with $\mathrm{N \omega}$-nitro-Larginine ( + L-NNA, $\left.10 \mu \mathrm{mol}^{-1}\right)$, glibenclamide (Glib, $\left.1 \mu \mathrm{mol}^{-1}\right)$, $\quad 1 \mathrm{H}-[1,2,4]$ Oxadiazolo[4,3-a]quinoxaline-1-one (ODQ, $10 \mu \mathrm{moll}^{-1}$ ) or a combination of L-NNA, apamin (Apa, $1 \mu \mathrm{moll}^{-1}$ ) and charybdotoxin (Chtx, $0.1 \mu \mathrm{moll}^{-1}$ ). Data are mean \pm s.e.m. All experiments were performed in the presence of indomethacin $\left(10 \mu \mathrm{moll}^{-1}\right)$. ${ }^{*} P<0.05$ compared to PSS; ${ }^{\dagger} P<0.05$ compared to Control. 
Table 2 Pharmacological parameters for UK-14,304-induced dilation of pressurised coronary endocardial arteries

\begin{tabular}{|c|c|c|c|c|c|c|}
\hline \multirow[t]{2}{*}{$U K, 14304$} & \multicolumn{3}{|c|}{ Control } & \multicolumn{3}{|c|}{$L V H$} \\
\hline & $\mathrm{p} D_{2}$ & $\mathrm{E}_{\max }(\%)$ & $\mathrm{n}$ & $\mathrm{p} D_{2}$ & $\mathrm{E}_{\max }(\%)$ & $\mathrm{n}$ \\
\hline PSS & $10.1 \pm 0.3$ & $79 \pm 6$ & 8 & $10.0 \pm 0.1$ & $25 \pm 4^{\dagger}$ & 5 \\
\hline + L-NNA & $10.2 \pm 0.3$ & $35 \pm 6^{*}$ & 7 & $9.8 \pm 0.4$ & $21 \pm 5$ & 5 \\
\hline$+40 \mathrm{mmoll}^{-1} \mathrm{KCl}$ & ND & $0 \pm 0^{*}$ & 5 & ND & $3 \pm 1 *$ & 5 \\
\hline+ Glib & $10.9 \pm 0.7$ & $35 \pm 10^{*}$ & 5 & ND & ND & \\
\hline+ ODQ & $9.9 \pm 0.7$ & $18 \pm 7 *$ & 4 & ND & ND & \\
\hline$+\mathrm{Apa}+\mathrm{Chtx}$ & $7.9 \pm 0.2^{*}$ & $39 \pm 8^{*}$ & 4 & ND & ND & \\
\hline$+\mathrm{L}-\mathrm{NNA}+\mathrm{Glib}$ & $9.6 \pm 0.7$ & $34 \pm 9 *$ & 4 & ND & ND & \\
\hline$+\mathrm{L}-\mathrm{NNA}+\mathrm{Apa}+\mathrm{Chtx}$ & ND & $3 \pm 1^{*}$ & 3 & ND & $2 \pm 1 *$ & 3 \\
\hline
\end{tabular}

Vascular sensitivity $\left(p \mathrm{D}_{2}\right)$ and maximal dilation $\left(E_{\max }\right)$ to the $\alpha_{2}$-AR agonist were measured in arteries isolated from control pigs and pigs with left ventricular hypertrophy $(\mathrm{LVH})$ following 2 months of aortic banding. Data are mean \pm s.e.m. All experiments were performed in the presence of indomethacin $\left(10 \mu \mathrm{moll}^{-1}\right)$. In the absence of KCl-PSS, arterioles were preconstricted with acetylcholine $\left(10 \mu \mathrm{mol} 1^{-1}\right)$. For drug concentrations, please refer to the section 'Study protocols'. ${ }^{*} P<0.001$ compared to PSS; ${ }^{\dagger} P<0.001$ compared to Control. ND: Not determined.
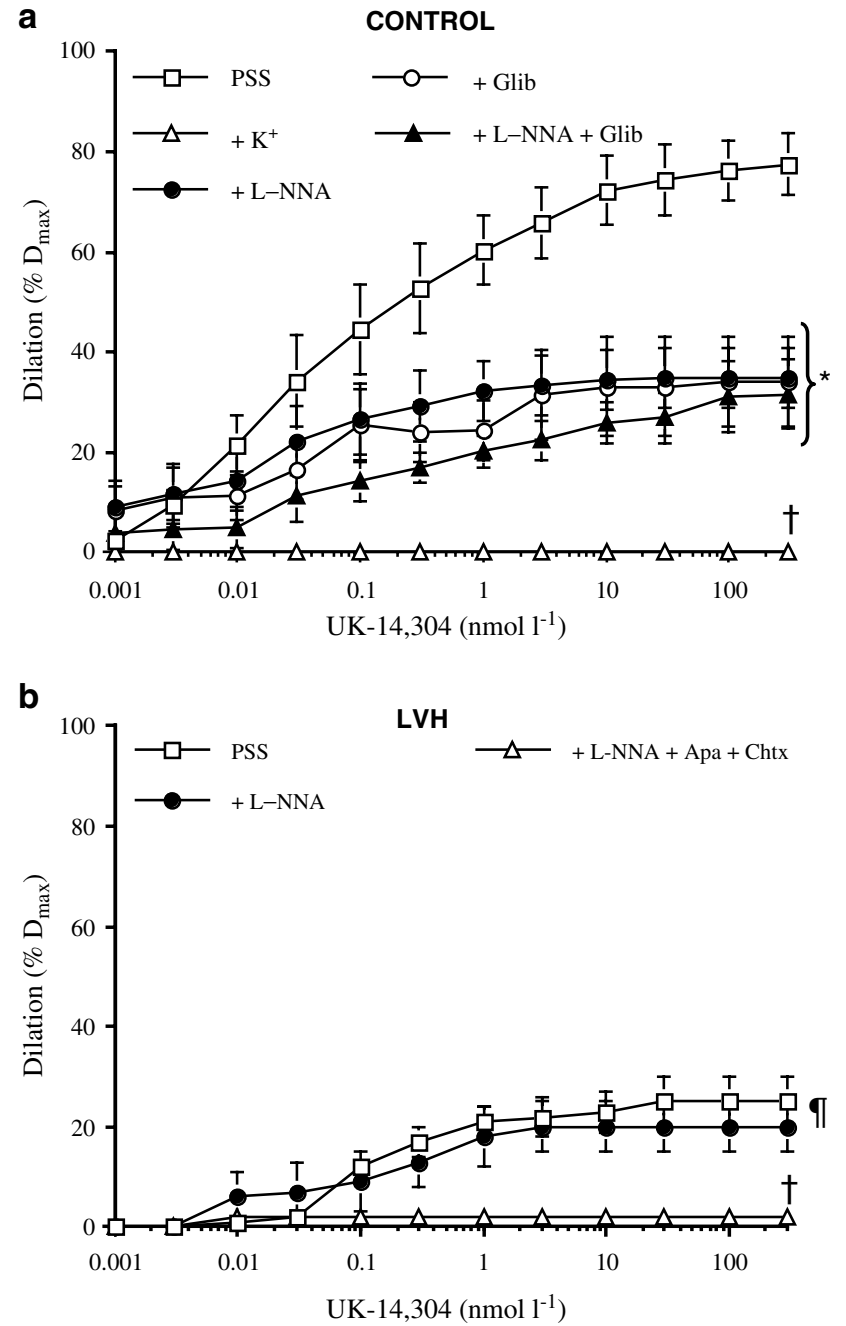

Figure 1 UK-14,304-induced dilation of isolated and pressurised endocardial coronary arteries isolated from (a) control and (b) LVH pigs. Experiments were performed in the absence (PSS) or presence of a depolarising solution $\left(+\mathrm{K}^{+}, 40 \mathrm{mmoll}^{-1} \mathrm{KCl} \mathrm{PSS}\right), N \omega$-nitroL-arginine ( $\left.+\mathrm{L}-\mathrm{NNA}, 10 \mu \mathrm{mol}^{-1}\right)$, glibenclamide (Glib, $1 \mu \mathrm{moll}^{-1}$ ) or a combination of L-NNA and glibenclamide or L-NNA and apamin $\left(1 \mu \mathrm{moll}^{-1}\right)+$ charybdotoxin $\left(0.1 \mu \mathrm{moll}^{-1}\right)$. Data are mean \pm s.e.m. of six to seven independent experiments. All solutions contained indomethacin $* P<0.05$ compared to PSS and with $\mathrm{K}^{+}$; ${ }^{\dagger} P<0.05$ compared to all groups; ${ }^{\top} P<0.05$ compared to PSS Control (a).
As shown in Table 2, glibenclamide produced similar inhibitions to L-NNA. The actions of these two inhibitors were not additive (Figure 1a)

To confirm the involvement of a putative EDHF in the L-NNA- and indomethacin-resistant dilation induced by UK14,304 , apamin $\left(1 \mu \mathrm{moll}^{-1}\right)$ and charybdotoxin $\left(0.1 \mu \mathrm{moll}^{-1}\right)$ were added to the organ bath. In the presence of the two $\mathrm{K}_{\mathrm{Ca}}$ channel inhibitors, UK-14,304-induced dilation was reduced by half in arteries isolated from control hearts (Table 2). In combination with L-NNA, UK-14,304-induced dilation was prevented in both groups (Table 2).

\section{Bradykinin-induced dilation}

BK-induced dilation was similar in the control and LVH group (Table 3 ). In the presence of high external $\mathrm{K}^{+}$, the concentration-response curve to $\mathrm{BK}$ was shifted to the right, whereas the maximal dilation induced by BK was slightly reduced in the control $(P<0.05)$ but not LVH group. In the presence of L-NNA, BK-induced dilation was unaltered and similar in both groups. Addition of ODQ in the presence of both indomethacin and $40 \mathrm{mmoll}^{-1} \mathrm{~K}^{+}$-PSS abolished the dilation to BK in both groups (Table 3). Glibenclamide did not affect BK-induced dilation (Table 3).

\section{Endothelium-independent dilation}

SNP-induced endothelium-independent dilation was similar in control and LVH coronary microvessels (Table 3). In depolarised conditions, vascular sensitivity and potency of SNP were not altered. ODQ, however, abolished $(P<0.001)$ the dilatory response to SNP in arteries isolated from both groups (Table 3). Glibenclamide had no influence on the vascular potency and efficacy of SNP (Table 3).

\section{Discussion}

The objectives of this study were to investigate the mechanisms of action of NO-induced dilation of pressurised coronary endocardial resistance arteries of healthy pigs and pigs with LVH induced by 2 months of aortic banding. Our data suggest that NO-induced dilation depends on endothelial $\mathrm{K}_{\mathrm{ATP}^{-}}$ channels opening when stimulated by an $\alpha_{2}$-AR agonist. In 
Table 3 Pharmacological parameters for bradykinin (BK)- and sodium nitroprusside (SNP)-induced dilation of pressurised coronary endocardial arteries.

\begin{tabular}{|c|c|c|c|c|c|c|}
\hline \multirow[t]{2}{*}{$B K$} & \multicolumn{3}{|c|}{ Control } & \multicolumn{3}{|c|}{$L V H$} \\
\hline & $\mathrm{p} D_{2}$ & $\mathrm{E}_{\max }(\%)$ & $\mathrm{n}$ & $\mathrm{p} D_{2}$ & $\mathrm{E}_{\max }(\%)$ & $\mathrm{n}$ \\
\hline PSS & $11.0 \pm 0.3$ & $97 \pm 2$ & 8 & $10.7 \pm 0.7$ & $101 \pm 4$ & 5 \\
\hline + Glibenclamide & $10.6 \pm 0.4$ & $96 \pm 3$ & 3 & $9.2 \pm 0.1$ & $96 \pm 2$ & 3 \\
\hline + L-NNA & $9.6 \pm 0.4^{*}$ & $90 \pm 4$ & 5 & $9.5 \pm 0.2$ & $95 \pm 4$ & 5 \\
\hline$+40 \mathrm{mmoll}^{-1} \mathrm{KCl}$ & $9.7 \pm 0.2^{*}$ & $83 \pm 4^{*}$ & 7 & $10.0 \pm 0.3$ & $93 \pm 1$ & 8 \\
\hline$+\mathrm{KCl}+\mathrm{ODQ}$ & ND & $3 \pm 2 *$ & 3 & ND & $2 \pm 2 *$ & 3 \\
\hline \multirow[t]{2}{*}{$S N P$} & \multicolumn{3}{|c|}{ Control } & \multicolumn{3}{|c|}{$L V H$} \\
\hline & $\mathrm{p} D_{2}$ & $\mathrm{E}_{\max }(\%)$ & $\mathrm{n}$ & $\mathrm{p} D_{2}$ & $\mathrm{E}_{\max }(\%)$ & $\mathrm{n}$ \\
\hline PSS & $5.7 \pm 0.3$ & $83 \pm 8$ & 7 & $4.8 \pm 0.3$ & $66 \pm 9$ & 7 \\
\hline$+40 \mathrm{mmoll}^{-1} \mathrm{KCl}$ & $5.1 \pm 0.2$ & $72 \pm 4$ & 8 & $4.6 \pm 0.1$ & $83 \pm 10$ & 5 \\
\hline+ Glib & $5.5 \pm 0.3$ & $76 \pm 11$ & 4 & $4.5 \pm 0.4$ & $50 \pm 3$ & 5 \\
\hline + ODQ & ND & $4 \pm 3^{*}$ & 3 & ND & $2 \pm 2 *$ & 3 \\
\hline
\end{tabular}

Vascular sensitivity $\left(p \mathrm{D}_{2}\right)$ and maximal dilation $\left(\mathrm{E}_{\max }\right)$ were measured in arteries isolated from control pigs and pigs with left ventricular hypertrophy $(\mathrm{LVH})$ following 2 months of aortic banding. Data are mean \pm s.e.m. All experiments were performed in the presence of indomethacin $\left(10 \mu \mathrm{moll}^{-1}\right)$. In control conditions, arterioles were preconstricted with acetylcholine $\left(10 \mu \mathrm{moll}^{-1}\right)$. For drug concentrations, please refer to the section 'Study protocols'. ${ }^{*} P<0.001$ compared to PSS. ND: Not determined.

$\mathrm{LVH}$, this mechanism is blunted and not compensated by a secondary endothelium-dependent pathway. We also found that endothelium-dependent dilation to BK and endotheliumindependent dilation to SNP do not depend on $\mathrm{K}_{\mathrm{ATP}}$-channels opening, and are not affected by LVH.

Addition of L-NNA, in the presence of indomethacin, reduced by $\approx 50 \%$ the maximal dilation to UK-14,304 in arteries isolated from control pigs. On the other hand, combined inhibition of $\mathrm{IK}_{\mathrm{Ca}}$ and $\mathrm{BK}_{\mathrm{Ca}}$ with apamin and charybdotoxin reduced by $\approx 50 \%$ the maximal dilation to $\mathrm{UK}$ 14,304. Hence, both NO and an apamin- and charybdotoxinsensitive factor, presumably EDHF (Edwards et al., 1998; Thollon et al., 2002), contribute to UK-14,304-induced dilation in arterioles isolated from control animals. Interestingly, however, $40 \mathrm{mmoll}^{-1} \mathrm{KCl}$-PSS alone abolished the UK14,304-induced dilation. This full block obtained in depolarising conditions suggested to us that a $\mathrm{K}^{+}$-dependent mechanism contributed to UK-14304-mediated, NO-dependent dilation.

It has been demonstrated that NO can interact directly with different $\mathrm{K}^{+}$channels such as ATP-sensitive $\mathrm{K}^{+}$channels $\left(\mathrm{K}_{\mathrm{ATP}}\right), \mathrm{BK}_{\mathrm{Ca}}$ and the voltage-gated $\mathrm{K}^{+}$channel $\left(\mathrm{K}_{\mathrm{v}}\right)$ (Bolotina et al., 1994; Miyoshi et al., 1994; Peng et al., 1996; Yuan et al., 1996; Li et al., 1997; Bychkov et al., 1998). These effects depend upon both the type of blood vessel and the species studied. For instance, $\mathrm{NO}$ can directly activate $\mathrm{K}_{\mathrm{Ca}}$ in smooth muscle cell membrane patches (inside-out configuration) isolated from the rabbit aorta in the absence of cGMP (Bolotina et al., 1994). Others have reported that adenosine can open endothelial $\mathrm{K}_{\mathrm{ATP}}$ channels through activation of a pertussis toxin-sensitive $G_{\mathrm{i}}$ protein. The endothelial hyperpolarisation increases the inward driving force for $\mathrm{Ca}^{2+}$, which leads to the production and release of NO (Hein \& Kuo, 1999). Similar to adenosine, endothelial $\alpha_{2}$-AR is coupled to $G_{\mathrm{i}}$ proteins and leads to vascular dilation (Véquaud $\&$ Thorin, 2001).

In order to verify that $\mathrm{K}_{\mathrm{ATP}}$ channels are involved in $\alpha_{2}$-ARdependent NO-induced dilation, we used glibenclamide. This reduced the maximal dilation as efficiently as L-NNA. Furthermore, combination of both L-NNA and glibenclamide did not further reduce the maximal dilation. This strongly supports the concept that L-NNA and glibenclamide blocked the same pathway. Hence, $\mathrm{K}_{\mathrm{ATP}}$ channels are implicated in $\mathrm{NO}$ induced dilation. There are two alternative pathways: first, UK-14,304-dependent $\mathrm{K}_{\mathrm{ATP}}$ channel activation leads to a rise in intracellular $\mathrm{Ca}^{2+}$ responsible for NOS activation (Hein \& Kuo, 1999). Second, UK-14,304-dependent phospholipase C activation leads to the release of $\mathrm{NO}$, which activates smooth muscle $\mathrm{K}_{\mathrm{ATP}}$ channels through a cGMP-dependent mechanism (Murphy \& Brayden, 1995). Our protocols did not allow for discrimination between the two pathways. However, the following results are suggestive of a direct $\alpha_{2}$-AR-dependent activation of endothelial $\mathrm{K}_{\mathrm{ATP}}$ channels:

- High external $\mathrm{K}^{+}$did not prevent BK-induced dilation of arterioles isolated from control pigs. This demonstrates that, in contrast to UK-14,304-induced dilation, (1) cGMPdependent NO dilation (sensitive to ODQ) is able to fully compensate EDHF inhibition and (2) NO does not activate smooth muscle $\mathrm{K}_{\mathrm{ATP}}$ channels to induce dilation as revealed by the lack of effect of glibenclamide on BK-induced dilation;

- As for BK, SNP-induced dilation was not affected under depolarising conditions with or without $\mathrm{K}_{\mathrm{ATP}}$ channel inhibition. As expected, the dilation was prevented by ODQ, demonstrating that SNP-induced dilation is NOmediated and cGMP-dependent.

Based on these findings, it is likely that $\alpha_{2}$-AR-dependent activation of endothelial $\mathrm{K}_{\mathrm{ATP}}$ channels accounts for $\mathrm{NO}$ production and release. Upon reaching the smooth muscle, NO stimulates the soluble guanylate cyclase, which triggers dilation. It is unlikely indeed that NO targets smooth muscle $\mathrm{K}_{\mathrm{ATP}}$ channels only when endothelial $\alpha_{2}$-AR are activated. Furthermore, and as discussed above, apamin and charybdotoxin reduced UK-14,304-induced dilation but did not abolish it. This is in agreement with the concept that endothelial $\mathrm{K}_{\mathrm{Ca}}$ channels accounts for EDHF-mediated dilation (Edwards et al., 1998; Thollon et al., 2002), a mechanism distinct from $\mathrm{K}_{\mathrm{ATP}}$ channel-dependent NO production (Hein \& Kuo, 1999). 


\section{Effect of LVH on UK-14,304 induced dilation}

In arterioles isolated from pigs with $\mathrm{LVH}$, the maximal dilation induced by UK-14,304 was severely impaired when compared to control. This endothelial dysfunction became apparent during $\alpha_{2}$-AR stimulation. No significant reduction in BK-induced dilation was observed. The lack of impairment of BK-mediated relaxation has been previously reported in pig coronary arteries 4 weeks postangioplasty (Thollon et al., 1999). Similarly, we previously reported that substance Pinduced relaxation of coronary arteries from atherosclerotic patients was not reduced whereas $\mathrm{ACh}$ induced a contraction (Thorin, 2001). Hence, there is no global endothelial dysfunction in $\mathrm{LVH}$, but rather an impairment of selected pathways.

Inhibition of $\mathrm{NO}$ synthase did not further reduce the dilation induced by UK-14,304, demonstrating that the $\alpha_{2}$-AR-dependent pathway leading to NO production is altered, probably sparing the EDHF pathway (L-NNA- and indomethacinresistant component). We confirmed that the remaining dilation was only attributable to a putative EDHF since the dilation was sensitive to a depolarising solution or to the combination of apamin and charybdotoxin, two $\mathrm{K}_{\mathrm{Ca}}$ channel blockers known to block this pathway (Adeagbo \& Triggle, 1993; Edwards et al., 1998; Beny \& Schaad, 2000; Brandes et al., 2000; Véquaud \& Thorin, 2001; Thollon et al., 2002). The limitation of our approach is the absence of membrane potential determination to confirm that repolarisation of the smooth muscle is responsible for the apamin- and charybdotoxin-sensitive dilation.

The origin of this selective inhibition of the endothelial $\alpha_{2}$ AR pathway is unknown. In a previous study, we reported that $\alpha_{2}$-AR activation led to the release of NO through the activation of the PLC by the $\beta \gamma$-subunits of the $G_{\mathrm{i}}$ protein, whereas activation of a putative $\mathrm{K}^{+}$current was linked to the $\alpha_{\mathrm{i}}$-subunit (Véquaud \& Thorin, 2001). It is known that in pathological conditions leading to endothelial dysfunction, $G_{\mathrm{i}}$ but not $G_{\mathrm{q}}$ proteins are dysfunctional (Perrault et al., 1999). It is possible that in $\mathrm{LVH}$, similar selective alterations occur.

Myogenic tone is a reduction in diameter induced by an increase in intraluminal pressure. Although myogenic in nature, this contraction is largely influenced by the endothelium (Nguyen et al., 1999), as revealed by the rise in myogenic tone after inhibition of both NO and EDHF production by

\section{References}

ADEAGBO, A.S.O. \& TRIGGLE, C.R. (1993). Varying extracellular $\left[\mathrm{K}^{+}\right]$: a functional approach to separating EDHF- and EDNO related mechanisms in perfused rat mesenteric arterial bed. J. Cardiovasc. Pharmacol., 21, 423-429.

BENY, J.L. \& SCHAAD, O. (2000). An evaluation of potassium ions as endothelium-derived hyperpolarizing factor in porcine coronary arteries. Br. J. Pharmacol., 131, 965-973.

BOLOTINA, V.M., NAJIBI, S., PALACINO, J.J., PAGANO, P.J. \& COHEN, R.A. (1994). Nitric oxide directly activates calcium-dependent potassium channels in vascular smooth muscle. Nature, 368, 850-853.

BRANDES, R.P., BEHRA, A., LEBHERZ, C., BOGER, R.H., BODE-BOGER, S.M., PHIVTHONG-NGAM, L. \& MUGGE, A. (2000). $N(\mathrm{G})$-nitro-L-arginine- and indomethacin-resistant endothelium-dependent relaxation in the rabbit renal artery: effect of hypercholesterolemia. Atherosclerosis, 135, 49-55.

BYCHKOV, R., GOLLASCH, M., STEINKE, T., RIED, C., LUFT, F.C. \& HALLER, H. (1998). Calcium-activated potassium channels and nitrate-induced vasodilation in human coronary arteries. J. Pharmacol. Exp. Ther., 285, 293-298.
L-NNA combined with apamin and charybdotoxin (Table 1). $\mathrm{LVH}$, however, influenced myogenic tone regulation by the endothelium. In the presence of L-NNA, myogenic tone augmented, a result not observed in control vessels. This remains an observation for which more studies are required. Either the importance of constitutively released $\mathrm{NO}$ is augmented in $\mathrm{LVH}$, or the rise in the production of an endothelium-derived constricting factor, such as endothelin-1, is unmasked by NO withdrawal (Nguyen et al., 1999; Thorin et al., 1999; Kinlay et al., 2001). On the other hand, glibenclamide had no effect in vessels isolated from hearts with $\mathrm{LVH}$, which supports the concept that these channels are malfunctioning in this pathological setting.

\section{Clinical significance}

Previous work by Bache's group demonstrated that, in comparison with normal hearts, hypertrophied hearts have increased reliance on opening of $\mathrm{K}_{\mathrm{ATP}}$ channels to augment coronary blood flow during exercise (Melchert et al., 1999). This study demonstrated that, contrary to the normal heart, adenosine was not mandatory for exercise-induced coronary dilation. In addition, Lavallée's group reported that the stimulation of endothelial $\beta_{2}$-AR involved the opening of $\mathrm{K}_{\mathrm{ATP}}$ channels (Ming et al., 1997). Our data suggest therefore that these mechanisms would be impaired in LVH.

In conclusion, our data suggest that endothelium-derived $\mathrm{NO}$ induces a dilation that primarily depends on the opening of endothelial $\mathrm{K}_{\mathrm{ATP}}$-channels when stimulated by UK-14,304, an $\alpha_{2}$-AR agonist. In $\mathrm{LVH}$, this mechanism of action is blunted and not compensated by a secondary endotheliumdependent pathway. The impact of this pathway on the regulation of the perfusion of the endocardium still remains to be demonstrated.

We are grateful for the technical assistance of Mr. O. Malo. This work has been supported in part by the Foundation of the Montreal Heart Institute, the Heart and Stroke Foundation of Quebec (E.T.) and the Canadian Institute for Health Research (E.T.). L.P. Perrault is a scholar of the Fonds de la Recherche en Santé du Québec. E. Thorin is a scholar of the Heart and Stroke Foundation of Canada.

DI BELLO, V., PEDRINELLI, R., GIORGI, D., BERTINI, A., TALINI, E., MENGOZZI, G., PAlAGI, C., NARDI, C., DELl'OMO, G., PATERNI, M. \& MARIANI, M. (2002). Coronary microcirculation in essential hypertension: a quantitative myocardial contrast echocardiographic approach. Eur. J. Echocardiogr., 3, 117-127.

EDWARDS, G., DORA, K.A., GARDENER, M.J., GARLAND, C.J. \& WESTON, A.H. (1998). $\mathrm{K}^{+}$is an endothelium-derived hyperpolarizing factor in rat arteries. Nature, 396, 269-272.

EGASHIRA, K., SUZUKI, S., HIROOKA, Y., KAI, H., SUGIMACHI, M., IMAIZUMI, T. \& TAKESHITA, A. (1995). Impaired endotheliumdependent vasodilation of large epicardial and resistance coronary arteries in patients with essential hypertension. Hypertension, 25, 201-206.

HEIN, T.W. \& KUO, L. (1999). cAMP-independent dilation of coronary arterioles to adenosine. Role of nitric oxide, G proteins, and KATP channels. Circ. Res., 85, 634-642.

HOUGHTON, J.L., DAVISON, C.A., KUHNER, P.A., TOROSSOV, M.T., STROGATZ, D.S. \& CARR, A.A. (1998). Heterogeneous vasomotor responses of coronary conduit and resistance vessels in hypertension. J. Am. Coll. Cardiol., 31, 374-382. 
HOUGHTON, J.L., STROGATZ, D.S., TOROSOFF, M.T., SMITH, V.E., FEIN, S.A., KUHNER, P.A., PHILBIN, E.F. \& CARR, A.A. (2003). African Americans with LVH demonstrate depressed sensitivity of the coronary microcirculation to stimulated relaxation. Hypertension, 42, 269-276.

KINLAY, S., BEHRENDT, D., WAINSTEIN, M., BELTRAME, J., FANG, J.C., CREAGER, M.A., SELWYN, A.P. \& GANZ, P. (2001). Role of endothelin-1 in the active constriction of human atherosclerotic coronary arteries. Circulation, 104, 1114-1118.

KOZAKOVA, M., GALETTA, F., GREGORINI, L., BIGALli, G., FRANZONI, F., GIUSTI, C. \& PALOMBO, C. (2000). Coronary vasodilator capacity and epicardial vessel remodeling in physiological and hypertensive hypertrophy. Hypertension, 36, 343-349.

LI, P.L., ZOU, A.P. \& CAMPBELL, W.B. (1997). Regulation of potassium channels in coronary arterial smooth muscle by endothelium-derived vasodilators. Hypertension, 29, 262-267.

MALO, O., CARRIER, M., SHI, Y.F., TARDIF, J.C., TANGUAY, F.F. \& PERRAULT, L.P. (2003). Specific alterations of endothelial signal transduction pathways of porcine epicardial coronary arteries in left ventricular hypertrophy. J. Cardiovasc. Pharmacol., 42, 275-286.

MARCUS, M.L., DOTY, D.B., HIRATZKA, L.F., WRIGHT, C.B. \& EASTHAM, C.L. (1982). A mechanism for angina pectoris in patients with aortic stenosis and normal coronary arteries. N. Engl. J. Med., 307, 1362-1367.

MELCHERT, P.J., DUNCKER, D.J., TRAVERSE, J.H. \& BACHE, R.J. (1999). Role of $K_{\text {ATP }}$ channels and adenosine in regulation of coronary blood flow in the hypertrophied left ventricle. Am. J. Physiol., 277, H617-H625.

MING, Z., PARENT, R. \& LAVALlEE, M. (1997). $\beta_{2}$-Adrenergic dilation of resistance coronary vessels involves $\mathrm{K}_{\mathrm{ATP}}$ channels and nitric oxide in conscious dogs. Circulation, 95, 1568-1576.

MIYOSHI, H., NAKAYA, Y. \& MORITOKI, H. (1994). Nonendothelialderived nitric oxide activates the ATP-sensitive $\mathrm{K}$ channel of vascular smooth muscle cells. FEBS Lett., 345, 47-49.

MUNDHENKE, M., SCHWARTZKOPFF, B. \& STRAUER, B.E. (1997). Structural analysis of arteriolar and myocardial remodelling in the subendocardial region of patients with hypertensive heart disease and hypertrophic cardiomyopathy. Virchows Arch., 431, 265-273.

MURPHY, M.E. \& BRAYDEN, J.E. (1995). Nitric oxide hyperpolarizes rabbit mesenteric arteries via ATP-sensitive potassium channels. J. Physiol., 486, 47-58.

NGUYEN, T-D, VÉQUAUD, P. \& THORIN, E. (1999). Effects of endothelin receptor antagonists and nitric oxide on myogenic tone and $\alpha$-adrenergic-dependent contraction of rabbit resistance arteries. Cardiovasc. Res., 43, 755-761.

OPHERK, D., MALL, G., ZEBE, H., SCHWARTZ, F., WEIHE, E., MANTHEY, J. \& KUBLER, W. (1984). Reduction of coronary reserve: a mechanism for angina pectoris in patients with arterial hypertension and normal coronary arteries. Circulation, 69, 1-7.

PENG, W., HOIDAL, J.R. \& FARRUKH, I.S. (1996). Regulation of $\mathrm{Ca}^{2+}$-activated $\mathrm{K}^{+}$channel in pulmonary vascular smooth muscle cells: role of nitric oxide. J. Appl. Physiol., 81, 1264-1272.

PERRAUlT, L.P., BIDOUARD, J.P., JANIAK, P., VILLENEUVE, N., BRUNEVAL, P., VILAINE, J.P. \& VANHOUTTE, P.M. (1999). Impairment of G-protein-mediated signal transduction in the porcine coronary endothelium during rejection after heart transplantation. Cardiovasc. Res., 43, 457-470.
PICHARD, A.D., GORLIN, R., SMITH, H., AMBROSE, J. \& MELLER, J. (1981). Coronary flow studies in patients with left ventricular hypertrophy of the hypertensive type. Evidence for an impaired coronary vascular reserve. Am. J. Cardiol., 47, 547-553.

RAJAPPAN, K., RIMOLDI, O.E., CAMICI, P.G., BELLENGER, N.G., PENNELL, D.J. \& SHERIDAN, D.J. (2003). Functional changes in coronary microcirculation after valve replacement in patients with aortic stenosis. Circulation, 107, 3170-3175.

RAJAPPAN, K., RIMOLDI, O.E., DUTKA, D.P., ARIFF, B., PENNELL, D.J., SHERIDAN, D.J. \& CAMICI, P.G. (2002). Mechanisms of coronary microcirculatory dysfunction in patients with aortic stenosis and angiographically normal coronary arteries. Circulation, 105, 470-476.

SAVAGE, D.D., GARRISON, R.J., KANNEL, W.B., LEVY, D., ANDERSON, S.J., STOKES, J., FEINLEIB, M. \& CASTELLI, W.P. (1987). The spectrum of left ventricular hypertrophy in a general population sample: the Framingham study. Circulation, 75 (Suppl A), 126-133.

TANIYAMA, Y. \& GRIENDLING, K.K. (2003). Reactive oxygen species in the vasculature. Molecular and cellular mechanism. Hypertension, 23, 8019-8029.

THOLLON, C., BIDOUARD, J.P., CAMBARRAT, C., DELESCLUSE, I., VILLENEUVE, N., VANHOUTTE, P.M. \& VILAINE, J.P. (1999). Alteration of endothelium-dependent hyperpolarizations in porcine coronary arteries with regenerated endothelium. Circ. Res., 84, 371-377.

THOLLON, C., FOURNET-BOURGUIGNON, M.P., SABOUREAU, D., LESAGE, L., REURE, H., VANHOUTTE, P.M. \& VILAINE, J.P. (2002). Consequences of reduced production of NO on vascular reactivity of porcine coronary arteries after angioplasty: importance of EDHF. Br. J. Pharmacol., 136, 1153-1161.

THORIN, E. (2001). Different contribution of endothelial nitric oxide in the relaxation of human coronary arteries of ischemic and dilated cardiomyopathic hearts. J. Cardiovasc. Pharmacol., 37, 227-232.

THORIN, E., PARENT, R., MING, Z. \& LAVAlleE, M. (1999). Contribution of endogenous endothelin to large epicardial coronary artery tone in dogs and humans. Am. J. Physiol., 277, H524-H532.

TREASURE, C.B., KLIEN, J.L., VIT, J.A., MANOUKIAN, S.V., RENWICK, G.H., SELWYN, A.P., GANZ, P. \& ALEXANDER, R.W. (1993). Hypertension and left ventricular hypertrophy are associated with impaired endothelium mediated relaxation in human coronary resistance vessels. Circulation, 87, 86-93.

TREASURE, C.B., MANOUKIAN, S.V., KLIEN, J.L., VITA, J.A., NABEL, E.G., RENWICK, G.H., SELWYN, A.P., ALEXANDER, R.W. \& GANZ, P. (1992). Epicardial coronary responses to acetylcholine are impaired in hypertensive patients. Circ. Res., 71, 777-781.

VÉQUAUD, P. \& THORIN, E. (2001). Endothelial G protein betasubunits trigger nitric oxide - but not endothelium-derived hyperpolarizing factor-dependent dilation in rabbit resistance arteries. Circ. Res., 89, 716-722.

YUAN, X.Y., TOD, M.L., RUBIN, L.J. \& BLAUSTEIN, M.P. (1996). NO hyperpolarizes pulmonary artery smooth muscle cells and decreases the intracellular $\mathrm{Ca}^{2+}$ concentration by activating voltage-gated $\mathrm{K}^{+}$ channels. Proc. Natl. Acad. Sci. U.S.A., 93, 10489-10494.

(Received April 6, 2004 Revised June 29, 2004 Accepted July 8, 2004) 